\title{
Subcarrier Intensity Modulation-Spatial Modulation for Optical Wireless Communications
}

\author{
Yan Cheng , Seung-Hoon Hwang \\ 광 무선통신을 위한 SIM-SM 변조 \\ 정 암, 황 승 훈, \\ ABSTRACT
}

In this paper, we propose a novel modulation that combines the spatial modulation (SM) with the subcarrier intensity-modulation (SIM) for optical wireless communications. The performance of SIM-SM scheme is compared to a conventional SIM by computer simulation. For the spectral efficiency (SE) of $2 \mathrm{bits} / \mathrm{s} / \mathrm{Hz}$, the performance gain about $2 \mathrm{~dB}$ is achieved. As the $\mathrm{SE}$ increases to 3 bit or $4 \mathrm{bits} / \mathrm{s} / \mathrm{Hz}$, the $\mathrm{Eb} / \mathrm{NO}$ gain becomes about $5 \mathrm{~dB}$. It is shown the attenuation for the SIM is more serious than the SIM-SM according to increasing the number of the subcarriers.

Key Words : Subcarrier intensity modulation, Spatial modulation, Optical communication, wireless communication, AWGN channel

\section{I . Introduction}

Optical wireless communications (OWC) is an age-long technology that entails the transmission of information-laden optical radiation through the free-space channel. It offers a license-free spectrum with almost an unlimited data rate, a low cost of development and ease and speediness of installation, a number of unique advantages over its RF counterpart can be viewed in other literatures. As the differences between $\mathrm{OW}$ and RF systems, the conventional modulation techniques adopted in RF channels cannot be readily applied in optical channels. Most practical OWC systems currently in use are based on the intensity modulation/ direct detection scheme (IM/DD) for outdoor as well as indoor applications ${ }^{[1]}$.
SIM technique as one of the intensity modulation (IM) schemes is a maturing, simply and cost-effective approach for exploiting bandwidth in analogue optical communication. It avoids the need for an adaptive threshold required by optimum-performing OOK-modulated FSO. It has also comparatively lower bandwidth requirement than the PPM. And it is more resilient to the turbulence induced fading for terrestrial FSO links ${ }^{[2]}$. However relative high average transmitted power due to the multiple subcarrier composite electrical signals, being the sum of the modulated sinusoids, requires a DC bias. Increasing the number of the subcarriers leads to increased average transmitted power. This factor results in poor power efficiency and places a bound on the number of subcarriers that can be accommodated when using multiple $\operatorname{SIM}^{[3]}$. As the

- First Author : 동국대학교 전자공학과 통신연구실, sherwincy@hotmail.com, 학생회원

○Corresponding Author : 동국대학교 전자전기공학부, shwang@dongguk.edu, 종신회원

논문번호 : KICS2013-07-276, 접수일자 : 2013년 7월 2일, 심사일자 : 2013년 8월 30일, 최종논문접수일자 : 2013년 12월 12일 
deterioration of the power efficiency in SIM can be seemed as the increasing the number of the subcarrier, we can use the principle of spatial modulation (SM) here to make the number of the subcarriers for data transmission is always one, thus can get a better power efficiency.

$\mathrm{SM}$ is a multi-transmitter technique for achieving increased data rate over the traditional on-off keying (OOK) and PPM signaling methods $^{[4,5]}$. The combination of SIM and SM can be seemed as a novel optical modulation which benefits from the advantages of both of two, improves the challenges in the conventional SIM as the poor power efficiency. According to the recent study, much of work has been on the combination of $\mathrm{SM}$ and other modulation schemes, such as $\mathrm{PPM}^{[6]}, \mathrm{PAM}^{[7]}$, and optical $\mathrm{OFDM}^{[8]}$. However, all of these schemes use the underlying principle of SM similarly as the exploitation of distinct multipath profiles received from different positions of transmitters. Unlike them, the SM in the proposed scheme works by the principle that only one subcarrier is active at any time instance.

In this paper, we propose a novel optical modulation which is the combination of SIM with SM. To best of our knowledge, SM along with SIM has not been introduced as a new optical modulation scheme. The SM used here is different from the conventional SM as the select objects are multiple subcarriers rather than the multiple transmitters, so it not only retains the values of the SM but also overcome the challenges of SM. Moreover the advantage of this novel scheme is that it enables a better power efficiency than conventional multiple SIM due to avoidance of transmitting data simultaneously on multiple subcarriers.

In Section II, the proposed novel optical modulation scheme which combined SM with SIM will be introduced detailedly. In Section III, under the different spectral efficiencies, we will compare the performance of the proposed scheme with the conventional SIM for the optical wireless communications. Finally, our conclusions will be given in Section IV.

\section{Combined SIM and SM Scheme}

\subsection{Subcarrier intensity modulation (SIM)}

Fig.1 shows the SIM-FSO link. The RF subcarrier signal, $\mathrm{m}(\mathrm{t})$, pre-modulated with the source data, $d(t)$, is used to modulate the intensity of the optical source PT. The following gives the general expression for $\mathrm{m}(\mathrm{t})$ in $\mathrm{N}-\mathrm{SIM}$ system:

$$
m(t)=\sum_{i=1}^{N} m_{i}(t)
$$

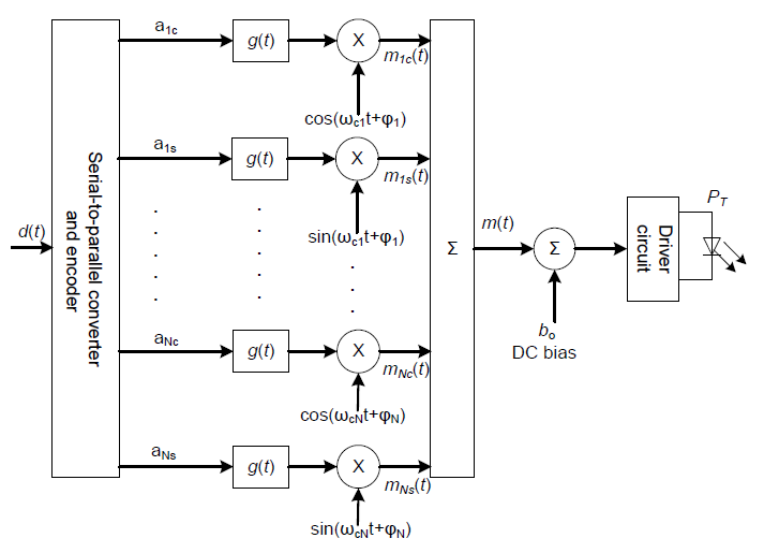

(a)

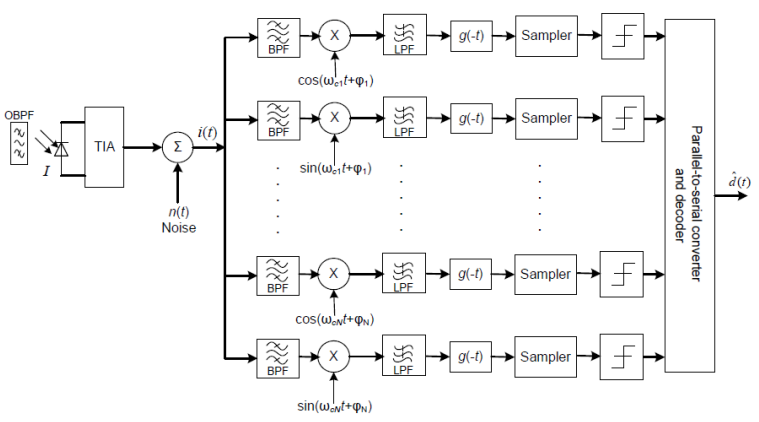

Fig. 1. Block diagram of SIM-FSO. (a) Transmitter and (b) receiver.

During a symbol duration, each RF subcarrier signal is generally represented by

$$
\begin{aligned}
& m_{i}(t)=g(t) a_{i c} \cos \left(w_{c i} t+\phi_{i}\right) \\
& +g(t) a_{i s} \sin \left(w_{c i} t+\phi_{i}\right)
\end{aligned}
$$

where $\mathrm{g}(\mathrm{t})$ is the pulse shaping function, and the subcarrier angular frequency and phase are 
represented by $\left[w_{c i}, \phi_{i}\right]_{i=1}^{N}, \quad\left[\alpha_{i c}, \alpha_{i s}\right]_{i=1}^{N}$ represents the symbol amplitude. A subset of this technique, in which the subcarrier frequencies are integer multiples of the fundamental subcarrier frequency is optical orthogonal frequency division multiplexing (OFDM). Direct detection is employed at the receiver to obtain the received electrical signal $\mathrm{i}(\mathrm{t})$, which can be modelled as

$i(t)=R I[1+\xi m(t)]+n(t)$

where $\mathrm{R}$ is PIN photo detector responsivity, I is received power, and the $\xi$ is the optical modulation index. The transmitted data are subsequently recovered from $\mathrm{i}(\mathrm{t})$ via coherent detection ${ }^{[1]}$.

\subsection{Spatial modulation (SM)}

The basic idea is to map a block of information bits to two information carrying units $^{[9]}$ :

1) a symbol that was chosen from a constellation diagram and

2) a unique transmit antenna number that was chosen from a set of transmit antennas (the so-called spatial-constellation diagram).

A simple example of encoding and decoding processed are shown in Fig. 2, when $\mathrm{Nt}=4, \mathrm{Nr}=1$, and $\quad \mathrm{M}=2 \quad(\mathrm{BPSK})^{[9]}$. Let $\overline{m_{\overline{n_{t}}}} \quad$ with $\overline{n_{t}}=1,2, \ldots, N_{t} \quad$ and $\quad \bar{m}=1,2, \ldots, M \quad$ be the transmitted message. The received signal can be written as follows ${ }^{[10]}$.

$$
r(t)=\tilde{s}\left(t \mid \overline{m_{n_{t}}}\right)+v(t)
$$

where $\left.\quad \tilde{s}\left(t \mid \overline{m_{n_{t}}}\right)=\left(s\left(\bullet \mid \overline{m_{n_{t}}}\right) \otimes h_{\overline{n_{t}}}\right)\right)$,

denotes convolution, $h_{\overline{n_{t}}}$ is the channel impulse response of the transmi-receive wireless link.

At the receiver, the optimal maximum likelihood (ML) detector with full Channel State Information (CSI) will be applied to retrieve the active transmit unit index as well as the BPSK modulated signal as follows:

$$
\begin{aligned}
& \widehat{m_{n_{t}}}=\operatorname{argmax} D\left(m_{n_{t}}\right) \\
& \text { for } n_{t}=1,2, \ldots, N_{t} \text { and } m=1,2, \ldots, M
\end{aligned}
$$

where $D(\bullet)$ for $n_{t}$ and $m$ is the decision metric defined in what follows:

$$
\begin{aligned}
& D\left(m_{n_{t}}\right)=R_{e} \int_{T_{m}} r(t) \widetilde{s^{*}}\left(t \mid m_{n_{t}} d t\right) \\
& -\frac{1}{2} \int_{T_{m}} \tilde{s}\left(t \mid m_{n_{t}}\right) \widetilde{s^{*}}\left(t \mid m_{n_{t}}\right) d t
\end{aligned}
$$

If the transmitted message is $\overline{m_{\bar{n}}}$, which results in switching on the $\overline{n_{t}}$-th transmit-antenna and sending the signal waveform $s\left(\bullet \mid m_{n_{t}}\right)$ out from it, the detector will be successful in detecting the transmitted message, if and only if

$$
\begin{gathered}
\max \quad D\left(m_{n_{t}}\right)=D\left(\overline{m_{\bar{n}}}\right) \\
\text { for } n_{t}=1,2, \ldots, N_{t} \text { and } m=1,2, . ., M
\end{gathered}
$$

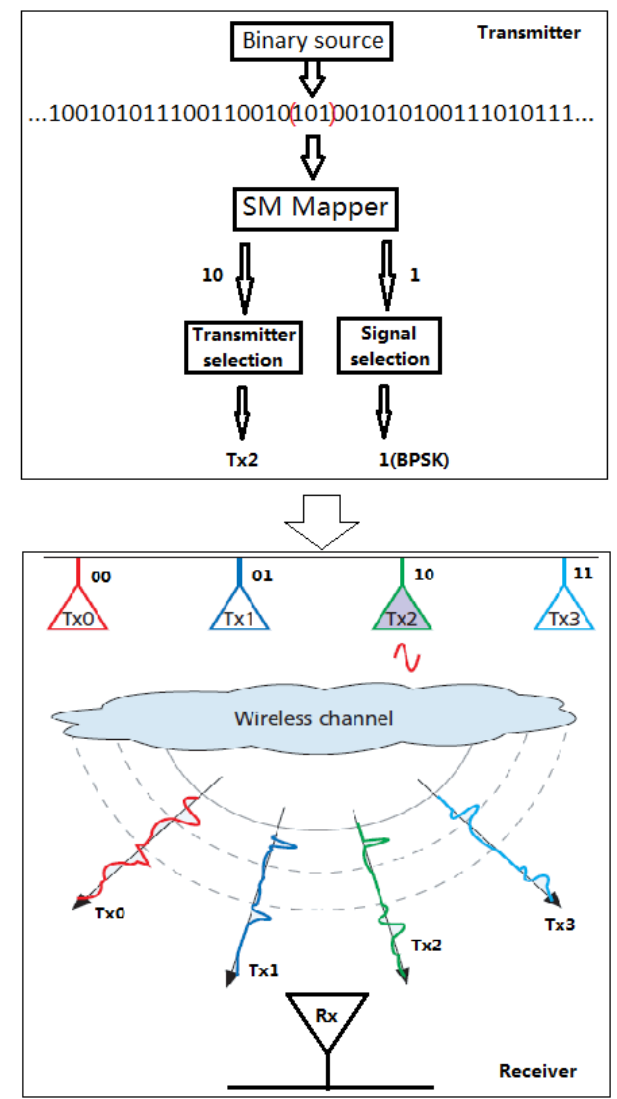

Fig. 2. SM: how it works. Setup: distance $(x, y)=$ Euclidean distance between signals $\mathrm{x}$ and $\mathrm{y}^{[9]}$. 


\subsection{Proposed system model}

Fig. 3 is diagram of the proposed SM with multiple-SIM consisting of Nsub subcarriers. At the transmitter, the data $d(t)$ is firstly mapped to two sub-blocks by SM mapper. For clear illustration, let us take an example. When the number of the subcarrier (Nsub) is 4 , the bits to be transmitted in four time slots are assumed to be $d(t)=\left[\begin{array}{llllllllllll}0 & 1 & 0 & 0 & 0 & 1 & 1 & 1 & 0 & 1 & 0 & 1\end{array}\right]$. Since Nsub=4 and $\mathrm{M}=2$, every $\log _{2} N s u b+\log _{2} M$ bits are transmitted at each time instant and grouped as follows ${ }^{[4]}$ :

$\left[010_{(t 1)} 001_{(t 2)} 110_{(t 3)} 101_{(t 4)}\right]^{T}$

where $[\vdots]^{T}$ denotes the transpose. According to the SM mapping rule in Table 1, the first two input bits will be mapped onto a single subcarrier from a set of four subcarriers to decide the subcarrier index that indicates which subcarrier is used for the data transmission in Fig. 4, and the last one bit will be mapped into a binary phase-shift keying (BPSK) constellation point. Note that only one subcarrier is modulated by "1" or " 1 " and the others are modulated by " 0 ". Thus the bits in this matrix are mapped to one of subcarriers, and then modulated by the BPSK modulator on the corresponding subcarrier, the resultant matrix $\mathrm{q}(\mathrm{t})$ is given by

$q(t)=\left[\begin{array}{cccc}0 & 1 & 0 & 0 \\ -1 & 0 & 0 & 0 \\ 0 & 0 & 0 & 1 \\ 0_{t 1} & 0_{t 2} & -1_{t 3} & 0_{t 4}\end{array}\right]$

Thus there is only one subcarrier signal will be used to modulate the intensity of the optical source. Prior to this, a D.C. signal is added to this subcarrier signal, to ensure that the optical source is appropriately biased at the center of its linear dynamic range so as to accommodate the full swing of sinusoidal subcarrier signal.
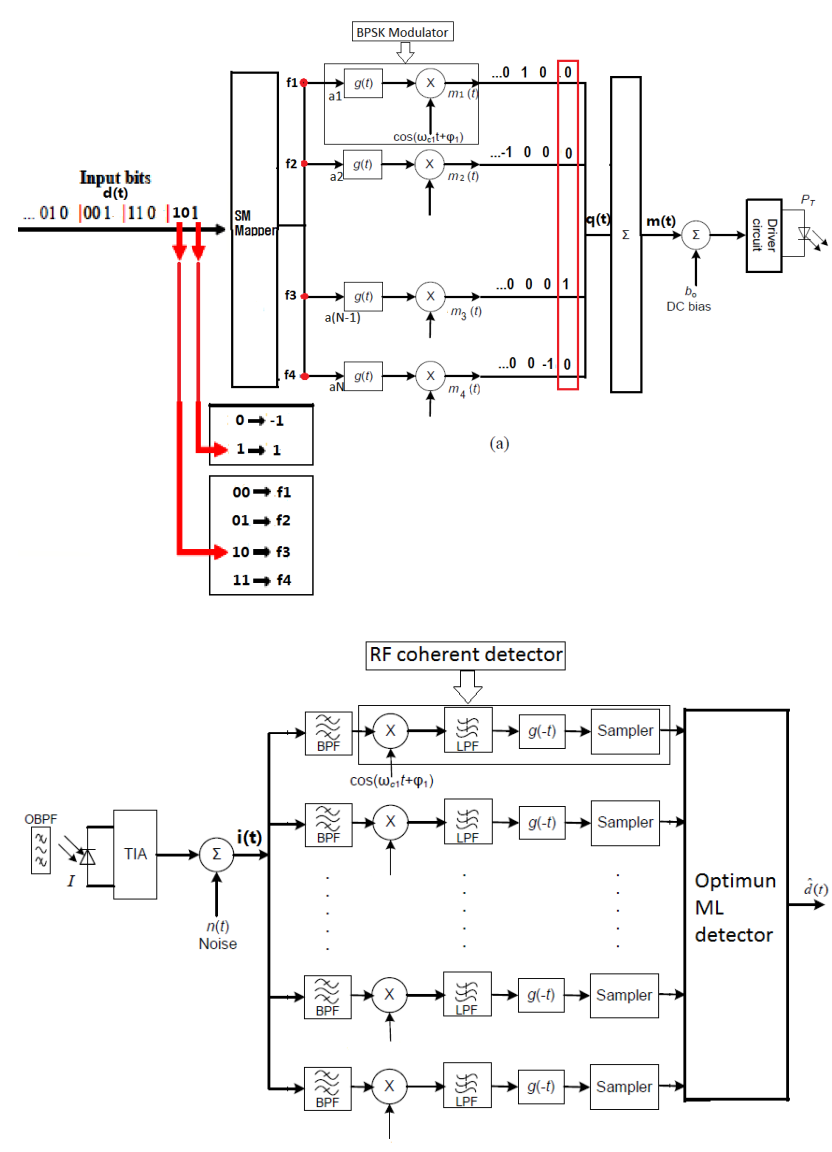

(b)

Fig. 3. The block diagram of SM+SIM system

At the receiver, the incoming optical radiation is converted into an electrical signal, $i(t)$ via the direct detection (DD) scheme. Electrical band-pass filters are used to capture the transmitted subcarrier $i_{c i}(\mathrm{t})$ followed by the standard RF coherent detector (which used in conventional SIM scheme) and ML detector (which used in SM scheme) to recover the transmitted signal $\widehat{d(t)}$. The system noise is modeled as an additive white Gaussian (AWGN) and no inter-symbol interference is considered here.

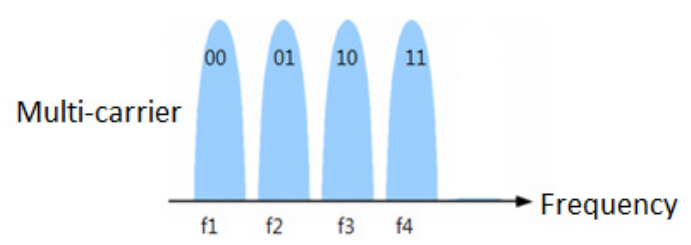

Fig. 4. Subcarrier index 
Table. 1. SM mapping table

\begin{tabular}{|c|c|c|}
\hline \multirow{2}{*}{$\begin{array}{c}\text { Input } \\
\text { bits }\end{array}$} & $\begin{array}{c}\text { N_sub=4, M=2 (BPSK) } \\
\text { index }\end{array}$ & $\begin{array}{c}\text { Transmit } \\
\text { symbol }\end{array}$ \\
\cline { 2 - 3 } & 1 & -1 \\
\hline 000 & 1 & 1 \\
\hline 001 & 2 & -1 \\
\hline 010 & 2 & 1 \\
\hline 011 & 3 & -1 \\
\hline 100 & 3 & 1 \\
\hline 101 & 4 & -1 \\
\hline 110 & 4 & 1 \\
\hline 111 & & \\
\hline
\end{tabular}

\section{Simulation results}

In this section, the error probability and throughput of the proposed SM with SIM will be showed, and compared with the performance of the SIM under different spectral efficiencies. The system described above is simulated using the Monte Carlo approach in Matlab.

\subsection{Simulation enviroment}

As mentioned above, the transmitted number of bits on one time instance is $\log _{2} N s u b+\log _{2} M$ for the proposed scheme ${ }^{[4]}$, and for the conventional SIM scheme is $N s u b \cdot \log _{2} M$. So when we need to compare the performances of two schemes under $2 \mathrm{bits} / \mathrm{s} / \mathrm{Hz}, 3 \mathrm{bits} / \mathrm{s} / \mathrm{Hz}, 4 \mathrm{bits} / \mathrm{s} / \mathrm{Hz}$, respectively, the number of the subcarriers are respectively $2,4,8$ for the proposed scheme, and 2, 3, 4 for the conventional SIM scheme, while the $\mathrm{M}=2$ (BPSK) for both schemes. The parameters used in the simulations are listed in the Table 2

Table 2. the Simulation Parameters

\begin{tabular}{|c|c|}
\hline Parameters & Values \\
\hline Data rate $\mathrm{Rb}$ & $1 \mathrm{Mbps}$ \\
\hline The subcarrier frequency & $14 \mathrm{MHz}-28 \mathrm{MHz}$ \\
\hline Sampling frequency & $70 \mathrm{MHz}$ \\
\hline $\begin{array}{c}\text { PIN photo detector } \\
\text { responsivity } \mathrm{R}\end{array}$ & 1 \\
\hline Constellation size $\mathrm{M}$ & 2 (BPSK) \\
\hline
\end{tabular}

\begin{tabular}{|c|c|}
\hline Spectral efficiency & $2,3,4 \mathrm{bits} / \mathrm{s} / \mathrm{Hz}$ \\
\hline Channel & AWGN \\
\hline Frame length Lf & 100 bytes \\
\hline
\end{tabular}

\subsection{Performance comparison}

From Fig.5 to the Fig.7, we can see the performance of the proposed scheme is better than the conventional SIM scheme over AWGN channel due to avoidance of transmitting data simultaneously on multiple subcarriers. In the Fig.5, for a spectral efficiency is $2 \mathrm{bits} / \mathrm{s} / \mathrm{Hz}$, the proposed scheme outperforms conventional SIM by about $2 \mathrm{~dB}$, then as the spectral efficiency increases to $3 \mathrm{bits} / \mathrm{s} / \mathrm{MHz}$ and $4 \mathrm{bits} / \mathrm{s} / \mathrm{MHz}$, as seen in Fig.6 and 7, the proposed scheme can outperform conventional SIM by about $4.9 \mathrm{~dB}$ and $5.3 \mathrm{~dB}$ respectively. So we can see the trends of attenuation for the conventional SIM is more serious than the proposed $\mathrm{SM}+\mathrm{SIM}$ as increasing the number of the subcarriers. It is because that for the conventional SIM, the performance degradation is due to attenuation of the power efficiency as increasing the number of the subcarrier, however, for the proposed SM+SIM, the performance degradation is not mainly due to the deterioration of the power efficiency as increasing the number of the subcarrier, but due to reduction of the spatial domain bits detection accuracy as increasing the number of the subcarriers.

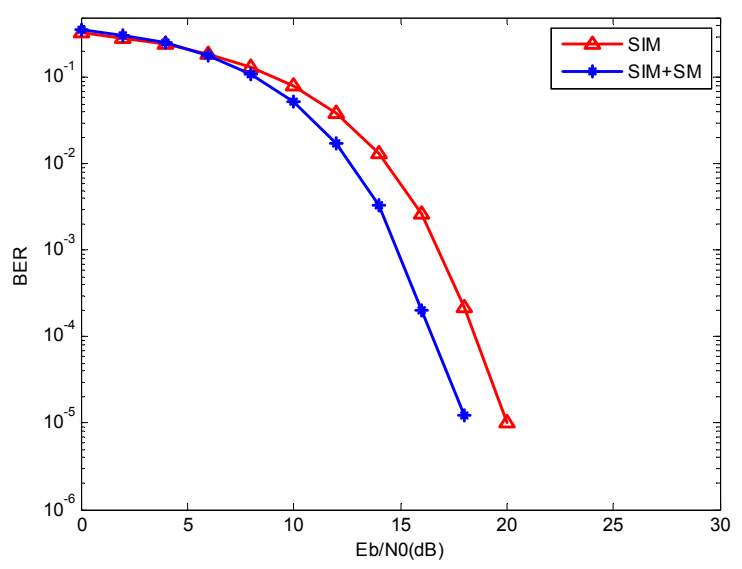

Fig. 5. Comparison on performance of the proposed SM+SIM and SIM for spectral efficiency of $2 \mathrm{bits} / \mathrm{s} / \mathrm{Hz}$ in AWGN channel 


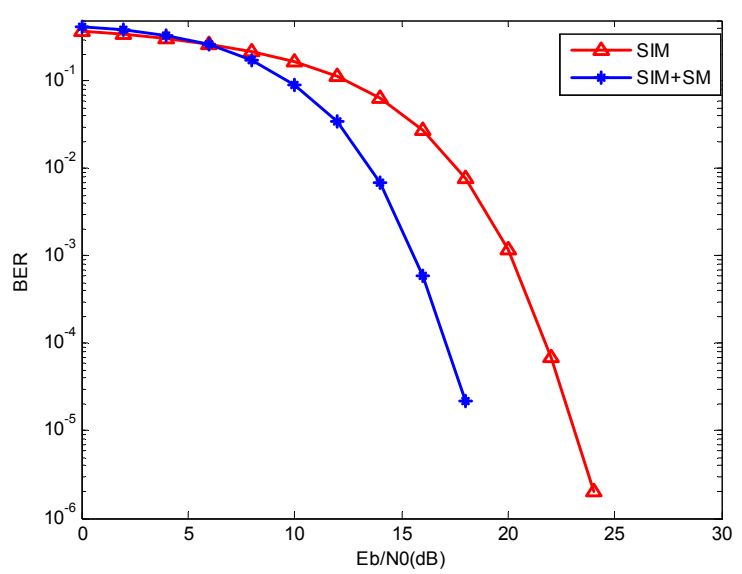

Fig. 6. Comparison on performance of the proposed $\mathrm{SM}+\mathrm{SIM}$ and SIM for spectral efficiency of $3 \mathrm{bits} / \mathrm{s} / \mathrm{Hz}$ in AWGN channel

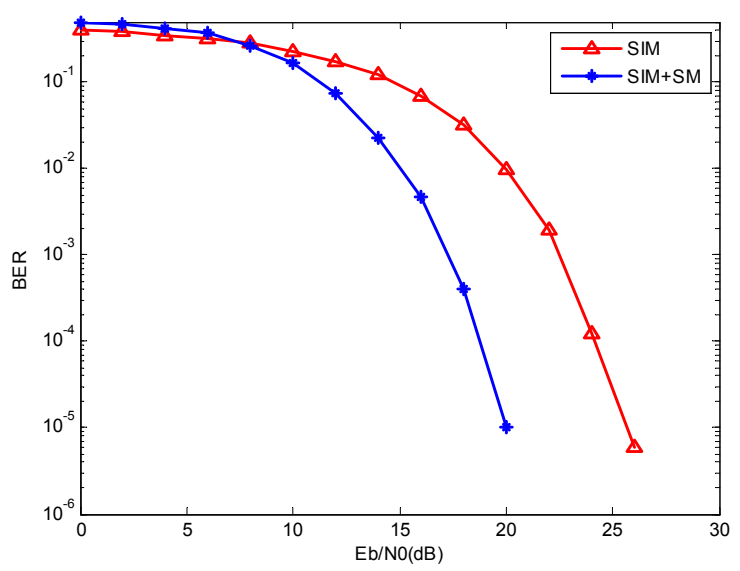

Fig. 7. Comparison on performance of the proposed SM+SIM and SIM for spectral efficiency of $4 \mathrm{bits} / \mathrm{s} / \mathrm{Hz}$ in AWGN channel

In additional, we also give the throughput of our proposed SIM+SM scheme compared with conventional SIM for different spectral efficiencies, which are showed from figure 8 to figure 10. In fig. 8 when the spectral efficiency is $2 \mathrm{bits} / \mathrm{s} / \mathrm{Hz}$, the conventional SIM scheme begins the successful data transmission at $\mathrm{SNR}=10 \mathrm{~dB}$, and reaches $100 \%$ successful transmission rate at $\mathrm{SNR}=20 \mathrm{~dB}$. While with the same starting $\mathrm{SNR}=10 \mathrm{~dB}$, the proposed SIM+SM scheme reaches $100 \%$ successful transmission rate at $\mathrm{SNR}=18 \mathrm{~dB}$, which is $2 \mathrm{~dB}$ less than the conventional scheme. Similarly, when the spectral efficiency is $3 \mathrm{bits} / \mathrm{s} / \mathrm{Hz}$, the proposed scheme needs $4 \mathrm{~dB}$ less SNR than the conventional scheme to begin the successful data transmission, and also needs $4 \mathrm{~dB}$ less SNR than the conventional scheme to reach the $100 \%$ successful transmission rate. When the spectral efficiency increases to $4 \mathrm{bits} / \mathrm{s} / \mathrm{Hz}$, the proposed scheme needs 6dB less SNR than the conventional scheme to reach the $100 \%$ successful transmission rate. So we can see that the throughput results here agree well with the previous points, which are showed in BER figures.

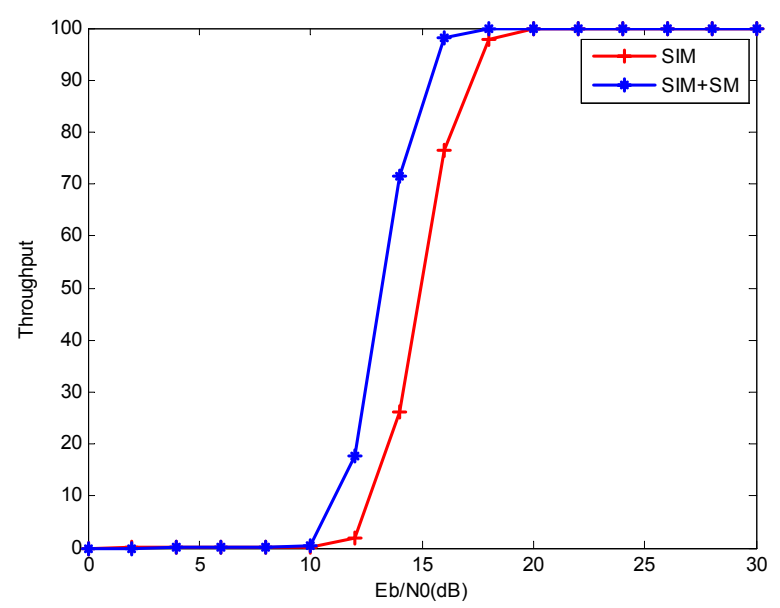

Fig. 8. Throughput versus SNR for propose SIM+SM and SIM scheme when spectral efficiency of $2 \mathrm{bits} / \mathrm{s} / \mathrm{Hz}$

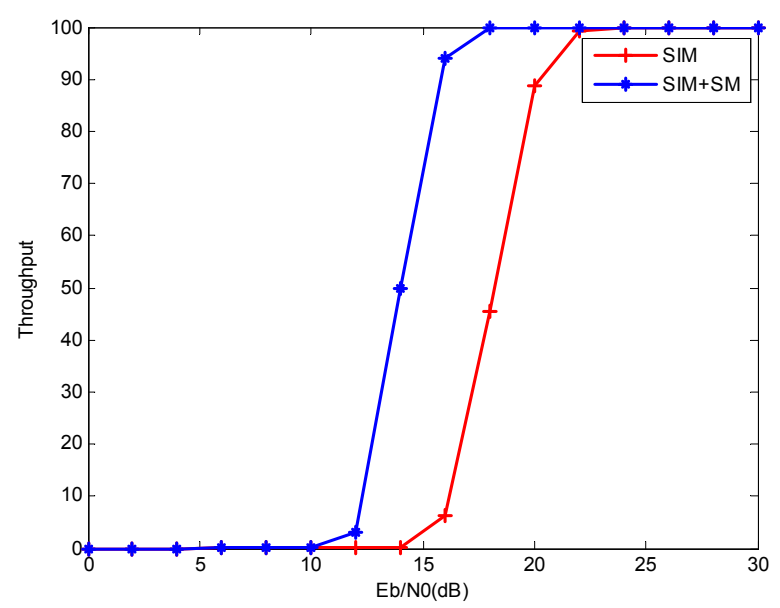

Fig. 9. Throughput versus SNR for propose SIM+SM and SIM scheme when spectral efficiency of $3 \mathrm{bits} / \mathrm{s} / \mathrm{Hz}$ 


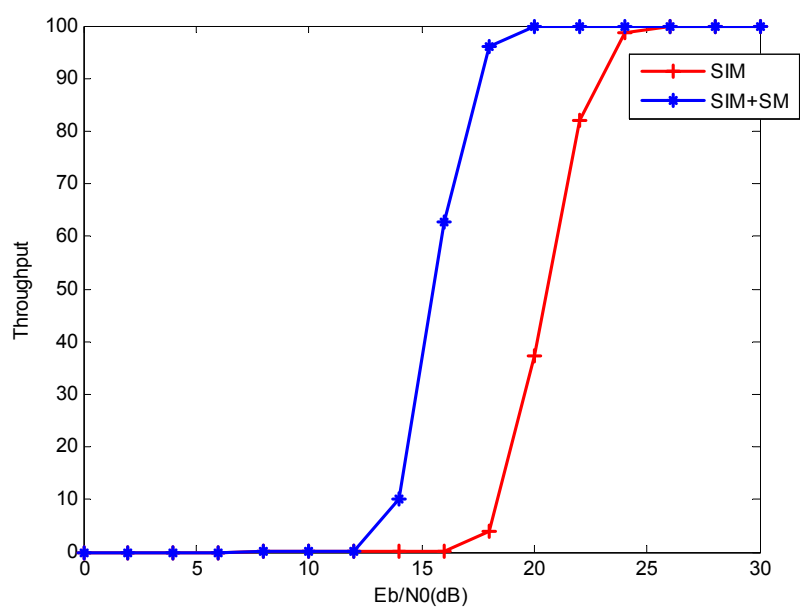

Fig. 10. Throughput versus SNR for propose SIM+SM and SIM scheme when spectral efficiency of $4 \mathrm{bits} / \mathrm{s} / \mathrm{Hz}$

\section{Conclusion}

In the paper, we combined the subcarrier intensity modulation (SIM) with spatial modulation (SM) due to its high power and bandwidth efficiency[5] in order to improve the poor power efficiency of the conventional SIM. As we know, for the conventional SIM scheme, the more the number of the subcarriers used for data transmission is, the poorer the power efficiency of the SIM is, as the result, deteriorating the performance of the SIM. However in the proposed SM+SIM, the SM here is used for selecting the subcarrier for data transmission, so no matter how many subcarriers there are, only one subcarrier is active for data transmission at any time instance, as the result, improve the power efficiency. The simulation results showed us that when the spectral efficiency is 2bits/s/Hz, 3bits/s/Hz, 4bits/s/Hz, respectively, the performance of the proposed scheme is better than the conventional SIM. However, as the combination of two different modulation schemes, both the transmitter side and receiver side have to be more complex than the conventional SIM. Furthermore, the computational complexity of ML detection increases exponentially according to the number of subcarriers, Future works will be focused on solving the complexity issue without any loss of the performance improvements.

\section{References}

[1] Z. Ghassemlooy, W. Popoola, and S. Rajbhandari, Optical Wireless Communications system and Channel Modeling with Matlab, CRC Press, 2012.

[2] W. O. Popoola, Z. Ghassemlooy, J. I. H. Allen, E. Leitgeb, and S. Gao, "Free-space optical communication employing subcarrier modulation and spatial diversity in atmospheric turbulence channel," IET Optoelectron., vol. 2, no. 1, pp. 16-23, Feb. 2008.

[3] R. You and J. M. Kahn, "Average power reduction techniques for multiple-subcarrier intensity-modulated optical signals," IEEE Trans. Commun., vol. 49, no. 12, pp. 2164 2171, Dec. 2001.

[4] R. Mesleh, H. Hass, S. Sinanovic, C. W. Ahn, and S. Yun, "Spatial modulation," IEEE Trans. Veh. Technol., vol. 57, no. 4, pp. 2228 - 2241, July 2008.

[5] R. Mesleh, H. Elgala, and H. Haas, "Optical spatial modulation," IEEE/OSA J. Optical Commun. Networking (JOCN), vol. 3, no. 3, pp. 234 -244, Mar. 2011.

[6] W. O. Popoola and E. P. Poves, "Spatial pulse position modulation for optical communications," J. Lightwave Technol., vol. 30, no. 18, pp. 2948-2954, Sep. 2012.

[7] T. Fath, H. Haas, M. D. Renzo, and R. Mesleh, "Spatial modulation applied to optical wireless communications in indoor LOS environments," in Proc. IEEE Global Commun. Conf., pp. 1-5. Houston, U.S.A., Dec. 2011.

[8] X. Zhang, S. Dimitrov, S. Sinanovic, and H. Haas, "Optimal power allocation in spatial modulation OFDM for visible light communications," in Proc. 2012 IEEE 75th Veh. Technol. Conf. (VTC Spring), pp. 1-5, Yokohama, Japan, May 2012.

[9] M. D. Renzo, H. Hass, and P. M. Grant, "Spatial modulation for multiple-antenna wireless systems: a survey," IEEE Commun. 
Mag., vol. 49, no. 12, pp. 182-191, Dec. 2011.

[10] M. D. Renzo and H. Hass, "Performance analysis of spatial modulation," in Proc. 2010 5th Int. ICST Conf. Commun. Networking (CHINACOM), pp. 1-7, Beijing, China, Aug. 2010.

[11] Y. Cheng, S. K. Ahn, and S. H. Hwang, "Combined subcarrier intensity modulation and spatial modulation for optical wireless communications," in Proc. Korea Inform. Commun. Soc. (KICS) Summer Conf., pp. 185-186, Jeju Island, Korea, June 2013.

[12] K. H. Park and Y. C. Ko, "Power and offset allocation for spatial-multiplexing MIMO system with rate adaptation for optical wireless channels," J. Korea Inform. Commun. Soc. (KICS), vol. 36, no. 1, pp. 8-18, Jan. 2011.

\section{정 암 (Yan Cheng)}

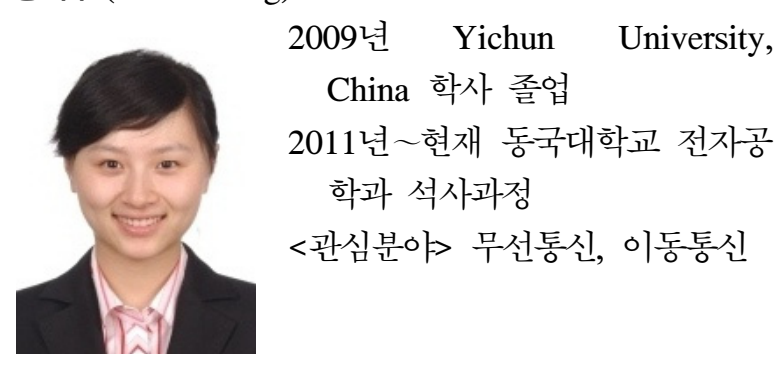

황 승 훈 (Seung-Hoon Hwang)

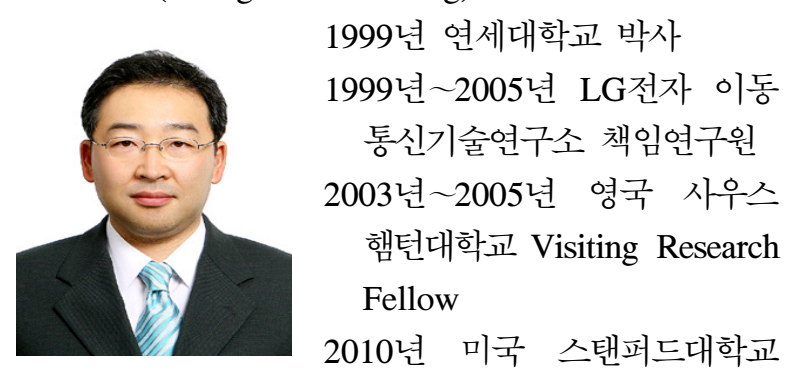

Visiting Professor

2005년 현재 동국대학교 교수

<관심분야> 무선 및 이동통신 시스템 및 요소기술, cognitive radio, M2M통신, 광무선통신 